\title{
South Africa: Improve facility management to increase nurse retention
}

Frontiers in Reproductive Health

Follow this and additional works at: https://knowledgecommons.popcouncil.org/departments_sbsr-rh

Part of the Demography, Population, and Ecology Commons, Family, Life Course, and Society Commons, International Public Health Commons, Maternal and Child Health Commons, and the Medicine and Health Commons

How does access to this work benefit you? Let us know!

\section{Recommended Citation}

"South Africa: Improve facility management to increase nurse retention," FRONTIERS OR Summary no. 63. Washington, DC: Population Council, 2007. 


\section{South Africa Quality of Care}

OR Summary 63

\section{Improve Facility Management to Increase Nurse Retention}

Both financial and nonfinancial factors influenced the tenure and job satisfaction of nurses at public maternity services in South Africa. Surveys suggest that strong management and fully equipped facilities could help redress staff turnover.

\section{Background}

South Africa's medical infrastructure is relatively well developed, but its maternal mortality rate remains high and numerous studies document poor maternal care. Shortages in nursing staff are believed to be a major factor in quality of care problems on maternity wards. A Population Council FRONTIERS study of antenatal care in rural clinics in Kwa-Zulu Natal showed between one-third and half of providers interviewed had worked at their clinics for less than a year (Chege et al. 2005).

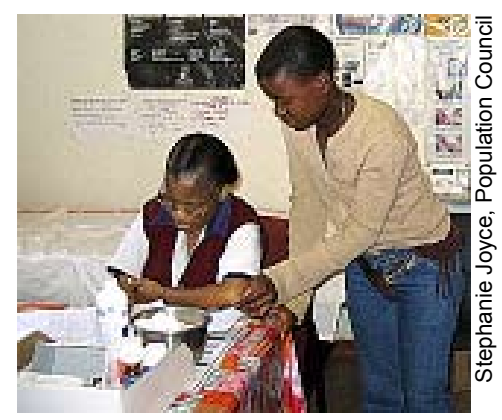

A nurse and client in a South African clinic.

In 2004, FRONTIERS and the Centre for Health Policy based at the University of the Witwatersrand followed up on the Kwa-Zulu Natal study and collaborated on a one-year study to document the factors affecting the tenure, motivations, and working conditions of maternal health nursing staff in three South African provinces-Kwa-Zulu Natal, Limpopo, and Mpumalanga. The study covered both nurses, who have a four-year college degree, and advanced midwives, who have additional training in midwifery and are considered essential to ensuring quality maternal health services. Data were collected through a questionnaire faxed to all public hospitals provid- ing maternal care services, a survey on nurses' motivation and decisionmaking, and interviews, as well as site visits to 15 hospitals and 27 clinics.

\section{Findings}

The investigation revealed a variety of problems leading to chronic disempowerment and demotivation of nurses. The multiple factors are linked to staffing, management, and policies, as follows:

- Turnover: The average vacancy rate for professional nurses was 23 percent in hospitals and 27 percent in clinics. Staffing vacancies varied by province, with the greatest proportion of clinical posts filled in Limpopo and the smallest in Mpumalanga (90\% versus 58\%). The average length of stay in a post was five to six years.

- Advanced midwives: About 80 percent of hospitals, but only 11 percent of clinics, employed an advanced midwife. Many advanced midwives expressed resentment that they were not paid more than professional nurses, despite their additional training. During the study period, 33 advanced midwives $(42 \%)$ left their post, but only 20 joined. Thus the staff members considered essential to high-quality maternal care were either not being deployed, or not retained.

- Management: Chronic problems between nurses and management fell into three categories: disorganized management; tension between staff and 
management; and managers' inability to institute change (including employee resistance to change). Managers were also demoralized, and many planned to leave.

- Hiring and promotion policies: Managers expressed frustration at their inability to fill posts or to obtain highly trained staff because this was done at the provincial level. Promotion for nurses was limited, and in about one-third of facilities, advanced midwives were working in better-paid areas, such as management.

- Morale: Survey responses by 147 nurses indicated serious morale problems. Over 40 percent of the respondents agreed with the statement that they "dreaded" the next day at work, felt unmotivated (over 50\%), could imagine working overseas $(50 \%)$, intended to leave their jobs $(40 \%)$.

- Specific factors predicted nurses' negative reactions:

- Unhappiness with their vocational choices, stress at work, and difficulty with change were significantly related to burnout and demotivation.

- Younger nurses, those working in hospitals, those with young children, and those working in urban areas were more likely to consider leaving or working overseas.

- Nurses in rural facilities had specific concerns, including poor accommodation and problems with transportation, facilities for children, and safety.

- Quality of care: Some hospital managers reported that there were serious problems with quality of care in maternity units. Problems included inadequate client monitoring, substandard reporting, and taking out frustrations on patients. Some managers said that work overloads led to this lack of care, but others cited poor work ethics.

- HIV: Neither nurses nor managers cited the HIV epidemic as a major factor in staffing problems. However, staffing and infrastructure problems affected nurses' ability to address HIV — causing them to miss critical training on HIV, for example, or preventing them from testing clients or referring them for antiretrovirals.

- Work decisions: Both financial and non-financial factors influence nurses' decisions on where to work. In a hypothetical choice exercise, good management and a well-equipped hospital were as important as a 15 percent pay increase in such decisions.

\section{Utilization}

- Motivational tools developed in this study have been used in Tanzania and Kenya. Elsewhere in South Africa, hospitals and midwives' organizations have used the tools to examine organizational problems and promote improved working conditions.

\section{Policy Implications}

- Policy initiatives to strengthen facility management, infrastructure, and supply chains may provide a more supportive environment for nurses. Policymakers also need to investigate hiring practices and pay scales. Decisions on staffing allocations should permit input at the facility level. Schemes need to be put into place to assist in retaining advanced midwifes in facilities.

Source: Penn-Kekana, Loveday et al. 2005. "Nursing staff dynamics and implications for maternal health provision in the context of HIV/ AIDS," FRONTIERS Final Report. Washington, DC: Population Council. Available on our website at www.popcouncil.org/frontiers/finalreports.html or by e-mail: frontiers@pcdc.org

This publication is made possible by the generous support of the American people through the United States Agency for International Development (USAID) under the terms of Cooperative Agreement No. HRN-A-00-98-00012-00. The contents are the responsibility of the FRONTIERS Program and do not necessarily reflect the views of USAID or the United States Government. 